\title{
WHAT IS IMPLICIT?*
}

\author{
Gert Helgesson \\ Department of Philosophy \\ Uppsala University \\ gert.helgesson@filosofi.uu.se
}

SUMMARY: This paper briefly surveys previous analyses of implicitness and proposes a new, two-dimensional account. The first dimension concerns whether an assumption follows or not in terms of analytical or contextual implications or because it is a reasonable interpretation. The second dimension concerns the intentions of the author. Both dimensions are needed for identifying implicit assumptions in critical analyses of texts. A definition of clear cases of implicit assumptions is given.

KEY WORDS: implication, implicature, implicit, pragmatic, presupposition, Robert H. Ennis, Paul Grice

RESUMEN: Este artículo examina brevemente análisis previos sobre lo implícito y propone una nueva explicación bidimensional. La primera dimensión es sobre si se sigue o no una suposición en términos de implicaciones analíticas o contextuales, o porque la interpretación es razonable. La segunda dimensión se ocupa de las intenciones del autor. Ambas dimensiones son necesarias para identificar suposiciones implícitas en los análisis críticos de textos. Se proporciona una definición de los casos claros de supuestos implícitos.

PALABRAS CLAVE: implicación, implicatura, implícito, pragmático, presuposición, Robert H. Ennis, Paul Grice

\section{Introduction}

In spite of the frequent use in philosophical argumentation of expressions like "implicit assumption" and "implicitly assumed", surprisingly little has been done to clarify what is meant, more specifically, by "implicit" in these contexts. Obviously, the expressions are used to point out that there are assumptions made,

* I am grateful to Erik Carlson, Sven Ove Hansson, and an anonymous referee of this journal for many helpful comments on earlier versions of this paper. 
or needed, which are not explicitly stated. But it still remains to explain how an unstated assumption can be a part of what is claimed. In Philosopher's Index over a thousand entries use "implicit" or "implicitly" in the presentation of their main points. A look at the abstracts of only a few of these makes one strongly inclined to think that there is more than one way in which an assumption may be implicit.

The purpose of this paper is to clarify the meaning of "implicit" and to develop criteria for the identification of implicit assumptions. Section 2 discusses previous work relevant to these tasks; section 3 brings up the need to look at intentions when analyzing what is implicit; section 4 clarifies the relation between intention and pragmatic implication; and section 5 combines what has been said so far into a two-dimensional analysis of implicitness.

\section{Previous work}

In English dictionaries you learn that "implicit" means: implied; understood or inferable; tacitly contained but not expressed. "Imply" is explained as: to involve or contain by implication; to mean indirectly, to hint; to enfold, to entangle. ${ }^{l}$ As P.H. NowellSmith remarks: "The metaphor underlying this word is that of something wrapped up in something else in such a way that if you have the latter you also have the former, as it were, "in the bag'."2

What is implicit, and thus unstated, is not necessarily less clear (or obvious) or less direct than what is explicitly stated. In other words, that an assumption is implicit does not mean that it is hidden and hard to find, or realized to be there only after some reflection, as examples below will show.

There are various ways in which we, in ordinary language, say that something implies something else. Facts, people, and texts may all imply something. Something may also be implied by

${ }^{1}$ Oxford English Dictionary (OED); Cassell Concise English Dictionary. These are not the only uses of the words, but the ones I take to be relevant here.

2 Nowell-Smith 1962, p. 3. 
our doing or saying something, or by our doing or saying it in a certain way or in a certain context. ${ }^{3}$ My focus will be on what is implicit in texts. However, much of what I say depends on ideas on what is implicit in utterances, i.e., in someone's saying something. I shall assume that much of what goes for utterances also goes for texts, which may be seen as written utterances. ${ }^{4}$

Few philosophers have addressed the question of how to understand "implicit" in connection to philosophical argumentation in general. ${ }^{5}$ The fullest account in the literature seems to be that given by Robert H. Ennis. In his paper "Identifying Implicit Assumptions", Ennis distinguishes between two different kinds of implicit assumptions: unstated premises and presuppositions. Unstated premises can be of two kinds: gap-fillers and back-ups. As indicated by the labels, gap-fillers add the needed but unexpressed premise to complete the argument, while backups support already stated premises, thus making them more compelling. ${ }^{6}$

Presuppositions have been extensively debated. ${ }^{7}$ A presupposition contained in "Jones has stopped beating her husband" is that Jones at one time did beat her husband. ${ }^{8}$ This assumption is not explicit, but to be able to stop doing something you must first do it, so it is implicit. Another well-known example of this kind is "The king of France is bald", which presupposes that there is a king of France. Similarly the statement "All my children are asleep" presupposes that the speaker has children.9

3 See Nowell-Smith 1962, p. 4.

${ }^{4}$ I think this is fairly uncontroversial. See Leech 1983, p. xiii.

5 There have been extensive discussions concerning both logical and pragmatic implication. These discussions have, however, been limited to the respective field of logic and linguistics.

${ }^{6}$ Ennis 1982, pp. 62-63.

7 Starting-points for the modern discussion were Moore 1944 and Strawson 1950. Presupposition was also discussed by Frege. On this, see Soames 1989, pp. 557-560. Horn 1996, p. 300, shows that presuppositions were discussed in some forms already by the scholastics.

${ }^{8}$ Ennis 1982, p. 76.

9 Hungerland 1960, p. 239. 
According to Ennis a presupposition of statement $X$ is, roughly speaking, "a proposition that, if false, would in a common (though imprecise) way of saying things, make $X$ neither true nor false". ${ }^{10}$ Since there is no king of France it is, according to this view, neither true nor false that the king of France is bald. However, this way of putting it is controversial, since you can also argue that the proposition about the king of France is false because the presupposition that there is a king of France is false. ${ }^{11}$ Leaving this discussion aside, it seems correct to say that the question of whether the statement is true or false does not really arise if the presupposition is false. Ennis also puts it in terms of questions, saying that "if the presupposition of the question is false, then the question, if it is a 'Yes'-or- 'No' type question, does not have 'Yes' or "No' as an answer". 12 If Jones never beat her husband, a "Yes" or "No" answer to the question "Has Jones stopped beating her husband?" does not communicate a correct picture of the situation.

Ennis' account of presuppositions is incomplete. "Presupposition" normally has a much broader meaning than the sense in which Ennis uses it. In this broader meaning that which is presupposed is held to be true, assumed to be the case, intended or meant, without this being stated. According to Robert Stalnaker, presuppositions are "propositions whose truth [the speaker] takes for granted, or seems to take for granted, in making his statement". 13 Scott Soames gives a number of examples:

10 Ennis 1982, p. 76. Ennis is not commited to the position that if the presupposition is false, then the statement is neither true nor false. That is why he adds "roughly speaking".

11 Grice 1981, p. 183, seems to agree with Ennis when he writes that "one does not feel very much inclined to say either that it is true that he is bald or that it is false that he is bald, but rather to say things like The question doesn't arise or He neither is nor isn't bald, etc.". Collingwood 1940 argues in a similar way, p. 26. This is also Strawson's position in Strawson 1950, which was criticized by Sellars in Sellars 1954 and defended in Strawson 1954. For modern expositions of the debate, see Horn 1996 and Soames 1989.

12 Ennis 1982, p. 77.

13 Quoted in Horn 1996, p. 306. Soames 1989, p. 553, gives a similar description. Stalnaker argues that it is necessary to adopt a pragmatic account of presuppositions — see Soames 1989, p. 566. 
"Bill regrets that he lied to Mary" presupposes that Bill lied to Mary, or believes that he did; "Harry managed to find the book" presupposes that finding the book required some effort; "Even Sam passed the test" presupposes that others, besides Sam, passed the test, and that Sam was among those least likely to do so. ${ }^{14}$

Paul Grice's account of conversational implicature is closely related to the notion of implicitness. ${ }^{15}$ According to Grice, conversational implicature

appears in such cases as that when somebody asks me where he can get some petrol and I say that there is a garage around the corner; here I might be said to imply, not just that there is a garage around the corner, but that it is open, and that it has stocks of petrol, etc. Or if, in response to a request for a testimonial for somebody who is a candidate for a philosophical job and whom I have taught, I write back and say that his manners are excellent and that his handwriting is extremely legible, I could be said to be implying that he was not all that good at philosophy. ${ }^{16}$

The major point for Grice is that conversational implicature concerns implications from someone's saying something and not from the very propositions or sentences used. He distinguishes between "what the speaker has said (in a certain favored, and maybe to some degree artificial, sense of 'said'), and what he has implicated (e.g. implied, indicated, suggested)". 17 Grice's distinction is sometimes described as that between the said and the meant-but-unsaid, ${ }^{18}$ but it would be more correct to say that it runs between the said and that which is meant-but-unsaid assuming that the speaker follows normal conversational rules. ${ }^{19}$

14 Soames 1989, p. 571.

15 Grice 1989, p. 86, says that "Implicature is a blanket word to avoid having to make choices between words like 'imply', 'suggest', 'indicate', and 'mean"".

16 Grice 1981, p. 184.

17 Grice 1989, p. 118.

18 See e.g. Horn 1996, p. 309.

19 Grice 1981, p. 185. I develop this point in section 4. 
Examples of conversational rules that Grice has in mind are "be relevant", "be perspicuous", and "do not say that which you believe to be untrue". 20

Grice suggests two tests by which conversational implicature can be identified: ${ }^{21}$

1) The possibility of cancellation. If you, "without logical absurdity", can attach a canceling clause, then you have identified a conversational implicature. ${ }^{22}$ For example: "He took off his trousers and got into bed, but I don't mean to suggest that he did those things in that order." Grice says that this shows that the original suggestion of a particular order in which things happened is not "part of the conventional meaning of the sentence". ${ }^{23}$ It is only implied by how we usually talk about such events.

2) Looking for other ways of saying what was originally said that would not carry the same implication. The point of doing this is that if "all the other ways seemed to be infected in the same way (to carry the implication) as the original, then that, so far as it went would be a good indication that the implicature did not attach to any particular words, but was something to do with conversational rules". ${ }^{24}$

Grice does not mean that these tests prove the presence of a conversational implicature, they only indicate the presence of one. The only proof, according to Grice, would be to "produce an account of how it would have arisen and why it is there". 25

20 Grice 1981, p. 184. Cf. Nowell-Smith 1962, who has similar ideas about "rules of rational discourse".

21 Grice 1981, p. 186, Grice 1989, p. 44.

22 This test distinguishes (at least sometimes) presuppositions from conversational implicatures. For example, it is not reasonable to say "Bill regrets that he lied to Mary - but by putting it this way I am not suggesting that he has lied to her". Cf. Horn 1996, pp. 309-310.

23 Grice 1981, p. 186. The example is Grice's.

24 Grice 1981, pp. 186-187.

25 Grice 1981, p. 187. For a further discussion of conversational implicature, see Horn 1996, pp. 309-317. 
Grice's conversational implicatures are examples of pragmatic implication, i.e., implications whose existence depends on "how utterances have meanings in situations". ${ }^{26}$ "Pragmatic implication" is a general label for what is communicated in particular situations or contexts apart from what the sentences used (always) mean. ${ }^{27}$

Kent Bach complements what has been said so far by bringing in what he calls completion and expansion. The need for completion arises when sentences are propositionally incomplete. Consider this sentence: "Steel isn't strong enough." It is syntactically well-formed but it does not express anything determinate - it has to be completed by answering the question "what for?" For example, steel might not be strong enough to stop the enemy tanks that are expected to attack. Many spoken and written sentences are of this kind and have to be completed somehow, e.g. by telling "in relation to what", "in addition to what", "what for", or "where". When such sentences are understood, the completion is in some sense provided by the context in which they are uttered. ${ }^{28}$

Expansions are not propositionally required in the same way, but according to Bach "[t]he proposition being communicated is a conceptually enriched or elaborated version of the one explicitly expressed by the utterance itself". For example, a boy accidentally cuts his finger and his mother comforts him by saying: "You're not going to die." The expansion of this sentence is most likely "from this cut", since she probably does not mean that he is immortal. ${ }^{29}$

${ }^{26}$ Leech 1983, p. x.

27 Nowell-Smith 1954, p. 85. According to Grant (1958, pp. 303, 319), pragmatic implication is what "imply" means in ordinary language. For a more extensive and critical discussion on Grice's ideas on implicature, see Davis 1998.

${ }^{28}$ Bach 1994, pp. 127-133. Bach gives many examples of incomplete sentences, with suggestions of how to complete them, for example: The lamp is cheap [relative to other lamps]. Strom is too old [to be a good senator]. The princess is late [for the party]. Even cowgirls sing the blues [in addition to cowboys].

${ }^{29}$ Bach 1994, pp. 133-139. Other examples by Bach: I haven’t eaten break- 
Pragmatic implication may also vary between groups. For example, saying that someone has "sensible political ideas" has widely differing implications in different political groups. What someone says or writes may be understood from experience either of how we generally communicate or of how some particular group communicates. Hence, a certain pragmatic implication may either be general within the language use of a society or exist only in the language use of a more limited group.

It should be pointed out that group context is relevant not only to pragmatic implication. It also often settles how words are used. For example, "model" primarily means one thing among architects, a very different thing among economists, and yet another thing in the fashion industry. By knowing the context in which they are spoken, or written, you often know which concept is intended. Context is relevant not only for interpreting the meaning of single words. It may also be crucial for interpreting the totality of a written or spoken message, by supplying a background against which it can be understood - it may for instance indicate what unstated assumptions are involved. For example, academic economists make claims that to the ordinary citizen seem to concern the function of real economies, while it is clear to these economists that the claims only concern model economies - this cannot be known from what is said, but from the context in which it is said.

Implicit assumptions may follow from explicit assumptions and context in different ways. Logical implication refers to something which undoubtedly follows. The same goes for semantic (conceptual) implication, as in "Daniel is a bachelor, therefore he is unmarried". Pragmatic implications do not have that absolute certainty. Nevertheless, there is often little or no doubt as to what is pragmatically implied. In other cases, it is less clear what an utterance means or what a certain passage of a text says. An interpretation is needed.

fast [today]. Jack and Jill are married [to each other]. Mr. Jones and Mrs. Smith are married [but not to each other]. 


\section{Intentions and interpretations}

An interpretation of a text may be based on criteria such as internal consistency, fidelity, contribution to gap-filling, plausibility, the absence of more promising competitors, etc. You may also need to look for allusions, imagery, and figures of speech (e.g. simile, metaphor and personification), which could "function to organize a work and become vehicles of meaning". The tone and style in which the text is written may also say something about what it is intended to communicate. ${ }^{30}$ The outcome of the interpretative process may be either a single most reasonable interpretation or a set of sufficiently reasonable interpretations.

Under normal circumstances, when you say or write something you do it for some reason, important or not. The speaker utters something with the intention to communicate something - what is in part given by pragmatic implication. That is why we may find it relevant to ask the author what a certain part of a text means. Any explanation from the author will not automatically do, of course, since we have independent criteria by which we judge the text, such as internal consistency. But if the answer is acceptable to us, we take it to say something about what is in the text and not only about the intentions of the author. ${ }^{31}$ And why shouldn't we? After all, the author knows what the text is meant to say. Therefore it seems that we should assume that she is right, unless we can show that what she says on the particular matter is inconsistent or otherwise does not fit with the rest of the text. As far as I can see, the only way to argue that the author's intentions never have anything to do with what is implicit in a text is to claim that the text does not mean anything apart from the literal meaning of the words and sentences in it,

30 Zigerell 1969, pp. 81-96, quote from p. 90.

31 "Oh, now I understand what you mean by this, and it all makes sense, but what does this mean?", pointing at the book or paper, would be an odd way to react to the author's answer. "No, this can't mean that if you mean what you say on page 53 " would, on the other hand, be a fully understandable reaction. 
as if there was no message, only the separate truth-values of the separate sentences (propositions). ${ }^{32}$

If we accept that the author's intentions may contribute to what is implicit in a text, should we not take assumptions implicit in various interpretations of the text to be assumptions implicit in the text as well? We have to be clear about what we mean here. We have already accepted that what is implied by the most reasonable interpretation of the text is to be taken as implicit in the text. But that is only to say that at least one interpretation is needed, namely the one that says what the text in fact means. Should we accept more than one interpretation? In some cases we may not be able to single out a most reasonable interpretation - a number of interpretations may be equally good. That means that we cannot choose between them. It does not mean that a number of interpretations, with different implications, can all be accepted simultaneously —as when interpretation $A$ implies $p$ and interpretation $B$ implies $\neg p$ (to claim that both $A$ and $B$ apply is then only reasonable under the assumption that the text supports logically incompatible statements). ${ }^{33}$

Maybe someone would like to argue that implicitness should be understood in terms of implicit-for, i.e., in a relative sense, leaving it up to the reader of a text to decide for herself what is implicit in it. This may be how we decide what we get out of reading a novel or watching a movie. But what reading a text does to you does not show what is in it. Reading an article in the newspaper may get you very upset, but that may depend on your misreading it. And your thinking that a certain conclusion logically follows from a set of premises cannot change the fact that it does not. So, for instance, what is logically implicit in a text is there whether you think so or not (there is no such thing

32 Support for the view that the author's intentions are relevant in interpreting texts is found in Hirsch Jr. 1967, chapter 1 and appendix I, particularly pp. 224-235, Knapp \& Benn Michaels 1992, Iseminger 1992, Carroll 1992.

33 It is worth pointing out that texts may be written in different manners and for different purposes: while e.g. the analytical philosopher generally aims for the unambiguous, the poet may intentionally make his texts ambiguous. What I say on implicitness primarily concerns texts intended to be unambiguous. 
as logically implicit for me but not for you). If implicitness is to be understood in a person-relative way it is also hard to understand how a theory or argument can be validly criticized. "If you don't like it on your interpretation, interpret it in some other way" seems to be a fully acceptable way to defend a theory under these conditions. If a certain interpretation is unreasonable and further implies some unacceptable assumptions, then this seems to be a perfectly good reason to reject the interpretation, not to reject the theory. To carry some weight in an argument, the interpretation has to be a good one. There may be many interpretations of a text, but if arguments against what is said in the text are to be of relevance they must concern the most reasonable interpretation (or one of the most reasonable interpretations) of it. Assumptions implied by some interpretation of the text are not automatically assumptions implicit in the text. ${ }^{34}$

\section{Intention and pragmatic implication}

As we saw in the previous section, intention matters to what is implicit in a text or in someone's saying something. Therefore interpretation of what is implicit is facilitated by identifying intentions, particularly in hard cases. We shall now take a step back and try to be more exact about what role intentions have in pragmatic implication.

As we have already noted, pragmatic implication concerns what is communicated in addition to what is said. What an author (or speaker) wants to communicate is, of course, not always understood by the receiver of the message. Thus, it is one thing what the author means and another thing what she in fact gets across. Assuming a skillful interpreter, who identifies what would be understood in such a context by such a message if the sender followed normal conversational rules, one can describe the difference as that between what the author means to imply and what is in fact implied.

Earlier, when discussing Grice, I mentioned that conversational implicature is sometimes said to concern "the meant-but-

34. See Hirsch Jr. 1967, chapter 2 and appendices I and II. 
unsaid", but that a more proper way to describe it would be to say that it concerns what is meant-but-unsaid assuming that the speaker follows normal conversational rules. According to the latter description, what is implicit is in principle independent of what the speaker actually means in a particular case. In Grice's example, where someone wants to buy petrol and I tell him "There's a garage around the corner", I am implying (or implicating) that the garage is open and has stocks of petrol even if I do not mean to communicate that. This is so because if I had followed normal conversational rules I would not have said what I said if I didn't mean to imply that. In other words, intention is relevant to conversational implicature, but not in a direct way — what the author, or speaker, means is not an essential component of what is pragmatically implied. If there is a discrepancy between intention and implicature, then that must be because the speaker deviates from normal standards of communication in that situation.

\section{A two-dimensional analysis of "implicit"}

I think the discussion so far shows that "implicit" can be analyzed along two different lines. Both these parameters are found in the literature, but they have previously not been combined into a single scheme. ${ }^{35}$ That will be done in this section.

One of these lines concerns whether an assumedly implicit assumption follows or does not follow from the text or utterance analyzed. At one extreme you find logical and other analytical implications. At increasing distance from it you find less and less compelling interpretations, until you reach implausible interpretations. Between the extremes three other categories seem relevant: contextual implication, the most plausible interpretation, and one of several equally plausible interpretations.

35 In the context of literary interpretation, those who have stressed one of the parameters have tended to argue explicitly against the relevance of the other. For an illustration of this, see the contributions in Iseminger (ed.) 1992. 
The category "contextual implication"36 is included in order to stress that there are instances between what follows analytically and what is the best interpretation. The point is that there are other ways for the non-explicit meaning to be given than through analytical inference, i.e., other cases where it is far-fetched to say that an interpretation is made. One type of instance is when the context clearly settles in what way a word is used (in section 2 "model" was used as an example of a word which has different meanings in different contexts) or how parts of the text should be understood. ${ }^{37}$ The other type I have in mind is unequivocal cases of pragmatic implication. Note that instances where there is ambiguity as to what is pragmatically implied do not fall into this category.

That which is presupposed in a presupposition should normally be placed in the "follows analytically" category, since what is presupposed depends on conceptual meaning. Perhaps what is presupposed sometimes also depends on context to some extent and then also belongs to the category of contextual implication. The example in section 2 about Sam ("Even Sam passed the test") may be an example of this, since it can be argued that exactly how much should be put into "even" here depends on context.

Put in the order from what most clearly follows to what does not follow we have the following categories: logical (analytical) implication - contextual implication - the most plausible interpretation — one of several plausible interpretations - implausible interpretations. I call this "the inferential scale". 38

36 The expression "contextual implication" has been used before (e.g. in Nowell-Smith 1954 and Hungerland 1960). However, I am not referring to any previous use here.

37 Since the context may settle the meaning of a word, e.g. what kind of "model" the text is about, it follows that what is logically and semantically implied sometimes is contextually dependent. This may seem to mess up the internal order of the categories on the inferential scale, but I think this is not a real problem since whatever content is settled by context is contextually implied.

38 A complicating factor when analyzing what is implicit in texts is that you cannot always regard everything that explicitly appears as something that belongs to a reasonable interpretation of that text. Misprints are an obvious 
The other dimension concerns whether the assumption is intended by the author or not. At one extreme the intended assumptions are all explicitly stated, and are thus not implicit. This case falls outside this study. At the other extreme the assumptions are not stated, not intended and not acceptable to the author. They are in this sense not implicit. Between the extremes we find the categories "acceptable to the author but not intended" and "intended by the author but not explicitly stated". Put in the order from intended to unacceptable to the author we have the following relevant categories: intended but not explicitly stated — not intended but acceptable to the author - not intended and not acceptable to the author. I call this "the intentionality scale". 39

These two dimensions add up to a total of 15 combinations to investigate (see Figure 1), each covering one candidate for what it is to be implicit.

Let us start by recognizing that the different categories on the scales give either a reason for taking a certain assumption to be implicit, a reason against taking it to be implicit, or no reason in any direction. Starting out with the inferential scale, we see that analytical implication gives a reason for taking the assumption to be implicit. The same goes for contextual implication and the most plausible interpretation. That an interpretation is implausible is a reason against taking it to be implicit, while being one of several plausible interpretations gives no reason in any direction. On the intentionality scale, something's falling

example. If it says in an otherwise reasonable text that two plus two equals five, then this claim should be disregarded. The most reasonable way to treat a certain claim in a text that does not at all fit with the rest may also be to disregard it, taking it to be something the author cannot have meant, but a temporary slip of the mind. Thus, a result of interpretation may be that some explicit claims are excluded from what is regarded when trying to understand what the text says. A consequence of this is that whatever is logically implied by the disregarded explicit claims is not implicit in the text. To formulate it more dramatically: an interpretation of the text may lead to the conclusion that part of what analytically follows from what is explicit in the text (as given) is not implicit in the text (as reconstructed).

39 It should be noted that the two scales are of logically different kinds. On the intentionality scale the various positions are logically independent. On the inferential scale this is not the case. 
into the category "is intended by the author" is a reason for taking it to be implicit, falling into the category "unacceptable to the author" is a reason against taking it to be implicit, while falling into the middle category (acceptable to the author but not intended) gives no reason in any direction.

What the outcome is in each of the 15 combinations depends on what factors are combined - clear cases are to be found when a reason for taking an assumption to be implicit (or not implicit) on one scale is combined with a similar or neutral reason on the other scale. When the reasons pull in different directions, the outcome depends on which factor is most compelling.

1-3 are obvious instances of implicit assumptions since whatever is logically or analytically implied by an argument is implicit in that argument - this is so regardless of whether it is acceptable to the author. 
Whatever is contextually implied or the most plausible interpretation and intended by the author $(4,7)$ is also implicit. This also goes for cases where what is contextually implied or the most plausible interpretation is combined with what is acceptable to the author, although not intended $(5,8)$. The latter would be exemplified by consequences of what is written that the author has not paid attention to.

10 covers cases where there are several plausible interpretations of what is implicit and the author intends one of them. Here the intention of the author should, in my view, be taken as a means to interpretation where other means are no longer available. 10 also covers cases where the author means to imply several plausible interpretations. If the interpretations intended by the author are mutually consistent, they are all implicit. If the combination is not consistent, then the combination is not plausible. Thus, it seems that whatever is covered by 10 is implicit in the text and that 10 covers cases where we can get a definite interpretation of a text only by asking the author what she means.

However, imagine a passage for which there are two interpretations, $p$ and $q$, each of which is plausible and intended by the author. Unfortunately they are jointly implausible. That is, $p$ is a plausible interpretation, and so is $q$, but $p \& q$ is not. This seems to lead us to the conclusion that $p$ is implicit, $q$ is implicit, and $p \& q$ is not implicit. Fortunately, we do not have to draw this conclusion. Since it is clear, independently of the author, that $p \& q$ is an implausible interpretation, $p$ and $q$ cannot both be implicit. The reasonable interpretation left is that either $p$ or $q$ is implicit, although it is undetermined which one it is. Thus, the intentions of the author cannot be used to determine what is implicit in cases like this.

11 also concerns an interpretation that is one of several plausible ones, but differs from 10 in that the interpretation is not intended by the author, but is acceptable to her. If two or more plausible interpretations are acceptable to the author, but are not jointly plausible, we run into a problem parallel to the special case of 10: what is acceptable to the author cannot be used to determine what is implicit in this kind of cases. 
On the other hand, if only one of several plausible interpretations is acceptable to the author, then it may seem reasonable to say that what follows from that interpretation is implicit in the text, although the support for that conclusion is fairly weak. The same goes if several mutually consistent plausible interpretations are acceptable to the author. ${ }^{40}$ However, if we look at the two scales concerning 11, we see that they are both neutral: "one of several possible interpretations" (the inferential scale) and "not intended by but acceptable to the author" (the intentional scale). Thus, the interpretation is not selected in the sense of being pointed out or favored on any of the scales, as they are in $1-5,7,8$, and 10 . Is it reasonable to consider an interpretation implicit if it is not pointed out on any scale? One may think that there should be some reason for regarding an assumption to be implicit, and that it is not enough that it cannot be excluded. Is the fact that an interpretation is the only one acceptable to the author such a reason?

Let us look at an example for guidance. Assume that the main character of a novel smokes a pipe, but that it is never said in the book what the color of the pipe is. Someone asks the author, and she finds all suggestions but one unacceptable. The one she accepts is that the pipe is black. Is it then implicit in the text that the pipe is black? The correct thing to say seems to be that it is left open in the text, and is not implicit, although the author obviously has an idea about how she means it to be. If one would respond that it is implicit in the text, it seems that one would have to accept anything as implicit that is left out in the text, consistent with the rest of the text, and exclusively acceptable to the author (exclusively in the sense that the pipe's blackness is exclusively accepted). That is to allow far too much. For example, what the author meant to put in the text but forgot

40 The same is also the case for disjunctions of incompatible interpretations: the disjunction may be implicit even if the disjuncts are incompatible. Thus, one may conclude that $A$ or $B$ is implicit (for example that the drunk driver at the scene of a car accident had a car that was either (all) black or (all) brown), while not both $A$ and $B$ can be (the car couldn't be all black and all brown). 
to - she may have forgotten to write a whole chapter that was pretty well thought out - cannot thereby be implicit in the text.

When the author realizes that she cannot accept any alternative to the pipe's being black, a reasonable response from her would be: "Now I realize that I intended the pipe to be black." The move from what is acceptable to the author to what is intended by the author hardly turns the pipe's being black into something that is implicit in the text. Rather it casts doubt over the general conclusion reached above about 10 .

The key to how this should be handled, I think, is that in the example with the pipe we do not need to know the color of the pipe in order to understand the novel. It is not significant and therefore there is no need for an interpretation. In other cases, an interpretation of some passage is badly needed in order for the text to be understandable, as may be the case when you read an advanced philosophical paper —or you may need an interpretation to remove ambiguities in an otherwise understandable text. Here you may be in a situation where you cannot leave the difficult part unattended if you are to understand what main points are made.

My suggestion is that when an interpretation of a particular part of a text is needed in order for the text to be understandable, or unambiguous, and there are several plausible interpretations to choose from, then the one intended by the author, or the one acceptable to her, affects what is implicit in the text. When no interpretation is needed (as is the case with the color of the pipe), then no interpretation on that matter concerns what is implicit. Thus, the basic issue is whether the assumption identified on a certain interpretation is needed for the text to be understandable and unambiguous. When it is, the author's intention is essential for that purpose.

This would leave us with two different answers regarding 10 and 11: in some cases they concern implicit assumptions, in others they do not. Whether an assumption is implicit or not has to be settled on a case-to-case basis. There are clear cases on both sides, which my examples are intended to illustrate, but there may also be ones that are more difficult to settle. Generally, when there really is a need for an interpretation in order for 
the text to be understandable, and unambiguous, 10 and 11 concern what is implicit whenever a definite interpretation can be produced. ${ }^{41}$

Some combinations are definitely not instances of implicitness. 15 is the clearest case - an implausible interpretation that the author has not intended and finds unacceptable does certainly not concern what is implicit in the text. The same goes for 14, which covers implausible interpretations not intended by the author but acceptable to her. There is no reason to consider any instance of what is not a plausible interpretation as implicit in the text. Thus, even though what is covered by 13 is intended by the author, it cannot be said to be implicit in the text.

It should be recognized that if the author is sufficiently rational and has sufficient time to reflect on what she has written, 13 would not be a real option since a rational author would not intend that which is implausible or impossible. Something similar can be said about 14 and 3 : the rational author with sufficient time to think things over would not accept the implausible; however, she would accept that which is logically implied. Nor would the special cases of 10 and 11 discussed above (where $p$ and $q$ are intended/accepted by the author even though $p \& q$ is not a plausible interpretation) be real options for a sufficiently rational author. Thus, cases $3,13,14$, and the special cases of 10 and 11 would not be available in a rational reconstruction of someone's writings, as long as the idea of full rationality is not abandoned. However, sometimes people do err, and therefore 3, 13,14 , and the special cases of 10 and 11 can all appear. If they do, the author has made a mistake.

In case 12 we are concerned with a plausible interpretation which is unacceptable to the author. There is nothing in favor of regarding this interpretation implicit, while something speaks against it. Thus, 12 falls out.

6 and 9 also refer to what is unacceptable to the author, but they have better support on the inferential scale. 6 refers to what

41 The last qualification is meant to exclude cases discussed under 10 above, where the author's intentions are not sufficient to produce a definite interpretation. 
is contextually implied, i.e., unequivocal cases of pragmatic implication and cases where the context settles how to understand single words or parts of the text. As was shown in the previous section, something may be pragmatically implied even though it is not intended by the author. Whenever there is a gap between pragmatic implication and author's intention, there is failure in communication - either the author fails to express herself in a sufficiently clear manner or she misleads on purpose. Obscurity about context may also cause communication failure. Still, if the text is in focus, as it is here, then 6 represents a case of implicitness. The same must be said about 9, which concerns cases where the most reasonable interpretation of a text is unacceptable to the author. As with 6, communication problems are involved, although not necessarily quite as dramatic. ${ }^{42}$

To summarize, 1-9 clearly concern what is implicit in a text, while 12-15 clearly do not. 10 and 11 sometimes do and sometimes do not, depending on whether the interpretation is needed (and useful) in order for the text to be understandable or unambiguous. The following definition can thus be given:

- An assumption is implicit in a text iff it is an instance of 1-9 or is an instance of 10 or 11 needed (and useful) in order for the text to be understandable and unambiguous.

\section{REFERENCES}

Bach, Kent, 1994, "Conversational Impliciture", Mind \& Language, vol. 9, pp. 124-162.

Carroll, Noël, 1992, “Art, Intention, and Conversation", in Iseminger (ed.) 1992, pp. 97-131.

Cassell Concise English Dictionary, 1994 ed., Cassell, London.

42 If we are concerned with a rational reconstruction of the thinking of a certain philosopher rather than a strict interpretation of the text, then it seems reasonable to pass a different judgment on 6 and 9 . As we have seen, lack of communication is central to 6 and 9. If we are more interested in what the author means than in what she in fact communicates, then the intentionality aspect becomes more important. 
Collingwood, R.G., 1940, An Essay on Metaphysics, Clarendon Press, Oxford.

Davis, Wayne A., 1998, Implicature. Intention, Convention, and Principle in the Failure of Gricean Theory, Cambridge University Press, Cambridge.

Ennis, Robert H., 1982, "Identifying Implicit Assumptions", Synthese, vol. 51, pp. 61-86.

Grant, C.K., 1958, "Pragmatic Implication", Philosophy, vol. 33, pp. 303-324.

Grice, Paul, 1989, Studies in the Way of Words, Harvard University Press, Cambridge.

—_, 1981, "Presupposition and Conversational Implicature", in Peter Cole (ed.), Radical Pragmatics, Academic Press Inc., New York, pp. 183-198.

Hirsch Jr., E.D., 1967, Validity in Interpretation, Yale University Press, New Haven.

Horn, Laurence R., 1996, "Presupposition and Implicature", in Shalom Lappin (ed.), The Handbook of Contemporary Semantic Theory, Blackwell Publishers, Oxford, pp. 299-319.

Hungerland, Isabel C., 1960, "Contextual Implication", Inquiry, vol. 3, pp. 211-258.

Iseminger, Gary, 1992, “An Intentional Demonstration?", in Gary Iseminger (ed.) 1992b, pp. 76-96.

- (ed.), 1992, Intention and Interpretation, Temple University Press, Philadelphia.

Knapp, Steven and Walter Benn Michaels, 1992, "The Impossibility of Intentionless Meaning", in Iseminger (ed.) 1992, pp. 51-64.

Leech, Geoffrey N., 1983, Principles of Pragmatics, Longman, London.

Moore, G.E., 1944, "Russell's Theory of Description", in Paul Arthur Schilpp (ed.), The Philosophy of Bertrand Russell, The Library of Living Philosophers, Northwestern University Press, Evanston.

Nowell-Smith, P.H., 1962, "Contextual Implication and Ethical Theory", Proceedings of the Aristotelian Society, Supplementary vol. 36, pp. 1-18.

- 1954, Ethics, Penguin Books, Harmondsworth.

Oxford English Dictionary, 1989, 2nd. ed., Clarendon Press, Oxford.

Sellars, Wilfrid, 1954, "Presupposing", The Philosophical Review, vol. 63, pp. 197-215.

Soames, Scott, 1989, "Presupposition", in D. Gabbay and F. Guenthner (eds.), Handbook of Philosophical Logic, vol. IV, D. Reidel, Dordrecht, pp. 553-616. 
Strawson, P.F., 1954, "A Reply to Mr. Sellars", The Philosophical Review, vol. 63, pp. 216-231. , 1950, "On Referring", Mind, vol. LIX, pp. 320-344.

Zigerell, James J., 1969, “On the Method of Explication”, Journal of Aesthetic Education, vol. 3, pp. 81-96.

Received August 17, 2000; revised February 14, 2002; accepted March 13, 2002 